\title{
PROPHYLAXIS OF VENOUS THROMBOEMBOLISM IN ORTHOPAEDIC SURGERY
}

Luiz Eugênio Garcez Leme', Guilherme Turolla Sguizzatto²

\section{ABSTRACT}

The relevance of prophylaxis of venous thromboembolism and its complications in orthopedic surgery is increasingly significant. This review discusses the pathophysiology of thrombus formation in general and orthopedic surgery, its incidence, pre- disposing factors and complications. It also presents an updated presentation and critique of prophylaxis currently available in our environment.

Keywords - Venous Thrombosis/prevention \& control; Embolism/prevention \& control; Orthopedics

\section{INTRODUCTION}

Prophylaxis of venous thromboembolism (VTE) and pulmonary embolism (PE) in orthopedic surgery, particularly in arthroplasties, continues to stir up considerable debate among health professionals, not only in Brazil, but worldwide.

This reality is part of an increasing awareness of two aspects: on one hand is the need to prevent avoidable complications with catastrophic repercussions, as can be the case with VTE and PE, and on the other, care to minimize the possible risks of bleeding associated with surgical procedures.

Studies in 1992 to compare enoxaparin and placebo in arthroplasties inform us that in the group submitted to prophylaxis, the presence of DVT detected by phlebography was $17 \%$, while in the placebo group, it was $53 \%(\mathrm{p}<0.0001)$. On the other hand, the incidence of more severe bleeding occurred in $6 \%$ of the placebo group, and in $8 \%$ of the enoxaparin group, without statistical significance $(\mathrm{p}=0.71)^{(1)}$.

In some countries, like the United States, this reality has created increasingly rigid demands, in the requirement to adopt mechanisms to protect patients in conditions of risk.
In fact, thromboembolic phenomena represent the more common complications in arthroplasties, including complications in the arteries ${ }^{(2)}$ and, in particular, in the veins, which are the greatest cause of death in the first three months after surgery, representing more than $50 \%$ of postoperative mortality ${ }^{(3)}$.

This condition leads to a growing level of demand that is incorporated into preventative care in major orthopedic surgeries in the United States ${ }^{(4)}$ and at the same time, in the large medical centers.

Thrombosis can occur as part of the natural physiological process. In normal situations, there is a balance between factors that hinder and those that promote clotting. An alteration to this balance can lead to untimely clotting. On the other hand, clotting failures can lead to hemorrhage.

\section{The Virchow's triad}

More than 150 years ago, Rudolf Virchow apud Merli $^{(5)}$ described the triad of factors responsible for thrombogenesis. These include: venous stasis, endothelial damage, and hypercoagulation. As can be seen, these three factors are closely linked to orthopedic procedures, particularly major ones, like arthroplasties.

\footnotetext{
1 - Geriatric Doctor; Associate Professor, Department of Orthopedics and Traumatology, School of Medicine, USP - São Paulo, SP, Brazil.

2 - Geriatric Doctor, Institute of Orthopedics and Traumatology, Hospital das Clínicas, School of Medicine, USP - São Paulo, SP, Brazil.

Study conducted at the Institute of Orthopedics and Traumatology of the HC/FMUSP - São Paulo, SP.

Correspondence: Rua Dr. Ovídio Pires de Campos, 333 - Cerqueira César - 05403-010 - São Paulo, SP. Email:lueglem@usp.br

Received for publication: 3/13/2012, accepted for publication: 4/12/2012.
} 


\section{The clotting cascade}

The clotting mechanism consists of self-regulating processes that result in the production of a fibrin thrombus. These processes are controlled by inactive cofactors that, when activated, promote or accelerate clotting. These processes usually occur on the surfaces of the platelets or macrophages, or in the endothelial cells, and are initiated by two specific pathways: extrinsic and intrinsic.

The extrinsic pathway is initiated as a result of activation of tissue lipoproteins resulting from mechanical injuries such as trauma and/or surgery.

The intrinsic pathway involves circulating plasma factors.

Both pathways are found at the level of factor X, transformed into factor Xa. This factor promotes the conversion of prothrombin into thrombin (factor II), which, in turn, transforms the fibrinogen into fibrin, this being the key step for the formation of the thrombus.

The plasmin digests the fibrin, as well as inactivating the V and VIII factors and fibrinogen, restoring normal blood flow.

There are three anticlotting mechanisms that prevent the formation of thrombi: antithrombin III (ATIII), $\mathrm{C}$ and $\mathrm{S}$ proteins, and the extrinsic pathway inhibition (tissue factor).

When surgery and/or trauma occur, there is a decrease in circulating ATIII, instigating the clotting process. Studies have shown that this decrease in ATIII is greater, and remains for longer in total hip arthroplasties (THA) than in cases of general surgery. In patients with DVT diagnosed after surgery, the ATIII levels were low $^{(6)}$.

\section{Localization of the thrombi}

The majority of thrombi may develop in the deep veins of the calf, rising from here to the thigh; however, in up to $30 \%$ of clots, the primary origin may be higher up, in the iliofemoral venous segment, independent of any thrombi originating in the calf veins.

In terms of relationship with the operated limb, $80 \%$ of thromboses originate here, while in up to $20 \%$ of cases, they may originate in the healthy limb.

Most clots in the calf are small, and clinically insignificant. Likewise, proximal vein thrombosis may not be occlusive and asymptomatic, and in some cases, it regresses spontaneously, without any adverse effects. Meanwhile, there is an important link between proximal deep vein thrombosis and pulmonary embolism, and also between silent, non-occlusive thrombi and symptomatic or fatal pulmonary embolism ${ }^{(7,8)}$.

\section{The risks of venous thromboembolism in hospi- talized patients}

The risk of development of DVT in hospitalized patients is notably high, ranging from 10 to $20 \%$ in patients with clinical disorders and $80 \%$ or more in patients with spinal cord injury, or critical patients ${ }^{(9)}$.

Among hospitalized patients and those submitted to surgery, patients who have undergone surgery for cancer, or orthopedic surgery, are at higher risk (Table 1).

Table 1 - Absolute risk of DVT in hospitalized patients.

\begin{tabular}{c|c}
\hline Group of patients & Prevalence (\%) DVT \\
\hline Clinical patients & $10-20$ \\
\hline General surgery & $15-40$ \\
\hline Major gynecological surgery & $15-40$ \\
\hline Major urological surgery & $15-40$ \\
\hline Neurosurgery & $15-40$ \\
\hline Stroke & $20-50$ \\
\hline Arthroplasties of the hip or knee & $40-60$ \\
\hline Spinal cord injury & $60-80$ \\
\hline Major trauma & $40-80$ \\
\hline Rates based on DVT in patients not receiving thromboprophylaxis.
\end{tabular}

Source: Adapted from Geerts WH, et al. Prevention of venous thromboembolism: the Seventh ACCP Conference on Antithrombotic and Thrombolytic Therapy. Chest. 2004;126(Suppl 3):338S-400S

\section{Venous thromboembolism and orthopedic surgery}

The nature of orthopedic disorders and diseases, such as trauma, arthroplasties, particularly of the hip and knee, create a higher risk for the occurrence of venous thromboembolism.

The positioning of the limb during surgery, localized postoperative edema, and limitations in mobility immediately after surgery, all play a role in venous stasis and the consequent reduction of blood flow ${ }^{(10)}$.

During surgery, manipulation of the limb, heat reaction resulting from the use of cement, and other aggressions can also activate thrombogenic factors that will manifest tropism for areas of vascular lesion and stasis ${ }^{(11)}$. On the other hand, blood loss can reduce the antithrombin III levels and inhibit the endogenous fibrinolytic system, enabling the formation and growth of thrombi ${ }^{(12,13)}$, at all levels. 
During their evolution, many asymptomatic thrombi regress spontaneously without treatment, without extending this thrombus or evolving to $\mathrm{PE}$ or post-thrombotic syndrome (PTS) ${ }^{(14)}$. Only one in eight thrombi identified by the venography will evolve to symptomatic $\mathrm{DVT}^{(15)}$, while proximal thrombi (above the poplipteal vein) have a higher likelihood of being symptomatic. However, around $10 \%$ of deaths occurring after THA are related to PE. It is known that between 3 and $4 \%$ of all symptomatic cases of VTE evolve to fatal $\mathrm{PE}^{(16)}$.

Compared with other disorders that lead to hospitalization of patients, the rate of DVT among high-risk orthopedic patients is substantially higher, including in patients hospitalized for clinical complaints or even other surgeries. A study by Geerts et $\mathrm{al}^{(17)}$ showed that patients who did not use prophylaxis and were submitted to THA had a rate of DVT of $50-60 \%$, of which $20-30 \%$ were proximal. The total incidence was even higher in patients after TKA, with a rate of $60-85 \%$ of total DVT, but with a lower rate of proximal DVT of 9-20\%. Patients with hip fractures had a total rate of DVT of $30-60 \%$, of which up to $36 \%$ were proximal. In these same series, the risk of fatal PE was 0.4-12.9\% (Table 2).

Another important data is presented to us by Falck-Ytter et $\mathrm{al}^{(18)}$, who, in their work, give graphs comparing the cumulative evolution of VTE in the first 90 days postoperative, comparing non-prophylaxis with the use of LMWH.

From a temporal perspective, studies located the peak risk of DVT and PE at around the third and fourth weeks postoperative, for hospitalized patients ${ }^{(19)}$ (Figure 1).

Other cohort studies suggest that the peak manifestation of DVT occurs around the first month, and can remain up to the $12^{\text {th }}$ week $^{(20)}$.

An analysis of 11,607 patients submitted to total hip arthroplasty (THA) between 1976 and 1985 showed a relative risk of 2.85 for the occurrence of DVT and PTE as the cause of death in the first three months postoperative, when compared with the remainder of the year ${ }^{(21)}$.

When primary arthroplasties of the hip and knee were studied, the DVTs appeared to be more prevalent in the first group ${ }^{(22)}$ (Figure 2).
Table 2 - Risk of VTE after orthopedic surgery in patients who did not receive prophylaxis.

\begin{tabular}{c|c|c|c|c}
\hline & Total DVT & Proximal DVT & Total PTE & Fatal PTE \\
\hline Surgery & $\%$ & $\%$ & $\%$ & $\%$ \\
\hline TKA & $41-85$ & $05-22$ & $1.5-10$ & $0.1-1.7$ \\
\hline THA & $42-57$ & $18-36$ & $0.9-28$ & $0.1-2.0$ \\
\hline Hip fracture & $46-60$ & $23-30$ & $03-11$ & $0.3-7.5$ \\
\hline
\end{tabular}

Adapted from Geerts WH, et al. Prevention of Venous Thromboembolism: American College of Chest Physicians Evidence-Based Clinical Practice Guidelines. Chest. 2008;381S-453S.

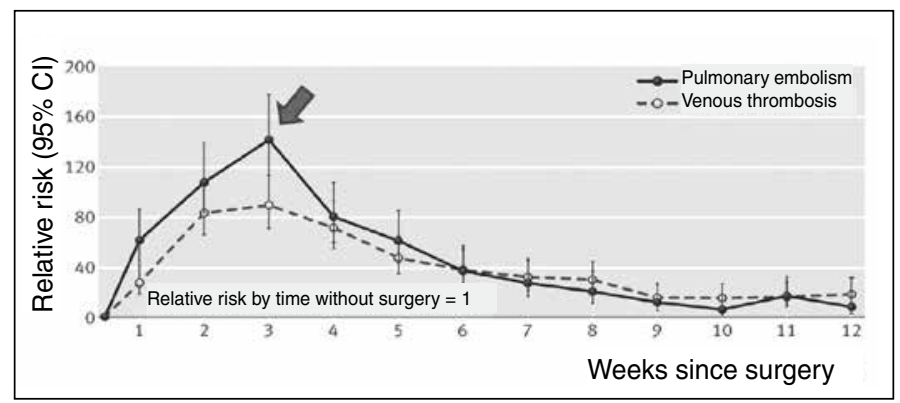

Figure 1 - Relative risks of pulmonary embolism and deep vein thrombosis over time.

Adapted from Sweetland S, et al. Duration and magnitude of the postoperative risk of venous thromboembolism in middle aged women: prospective cohort study. BMJ. 2009;339:b4583.

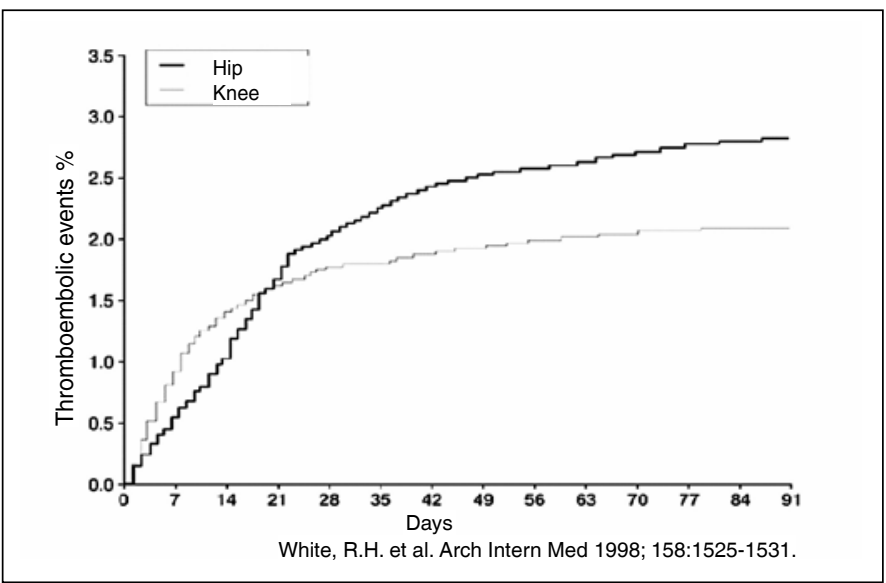

Figure 2 - Incidence of events/days after primary arthroplasties of the hip or knee (Kaplan-Meyer).

Adapted from White RH, et al. Arch Intern Med. 1998;158:1525-31.

\section{Pulmonary thromboembolism (PTE)}

Pulmonary thromboembolism may be the most feared complication of VTE. Its presentation is varied, and can range from fulminant conditions to mild dyspnea, or even a total absence of symptoms. The rate of lethality accompanies this heterogeneity, ranging from more than $60 \%$ to less than $1 \%$ of cases ${ }^{(23)}$.

Diagnosis is often difficult due to the variable symptoms, and the use of algorithms may be useful $^{(24)}$ (Figure 3).

Once the diagnosis has been made, treatment should begin immediately, and should clearly follow distinct parameters from those used for prophylaxis, 
with an initial phase of five days, which may extend to three months, or in cases of high risk of relapse, for the remainder of the patient's life ${ }^{(24)}$ (Figure 4).

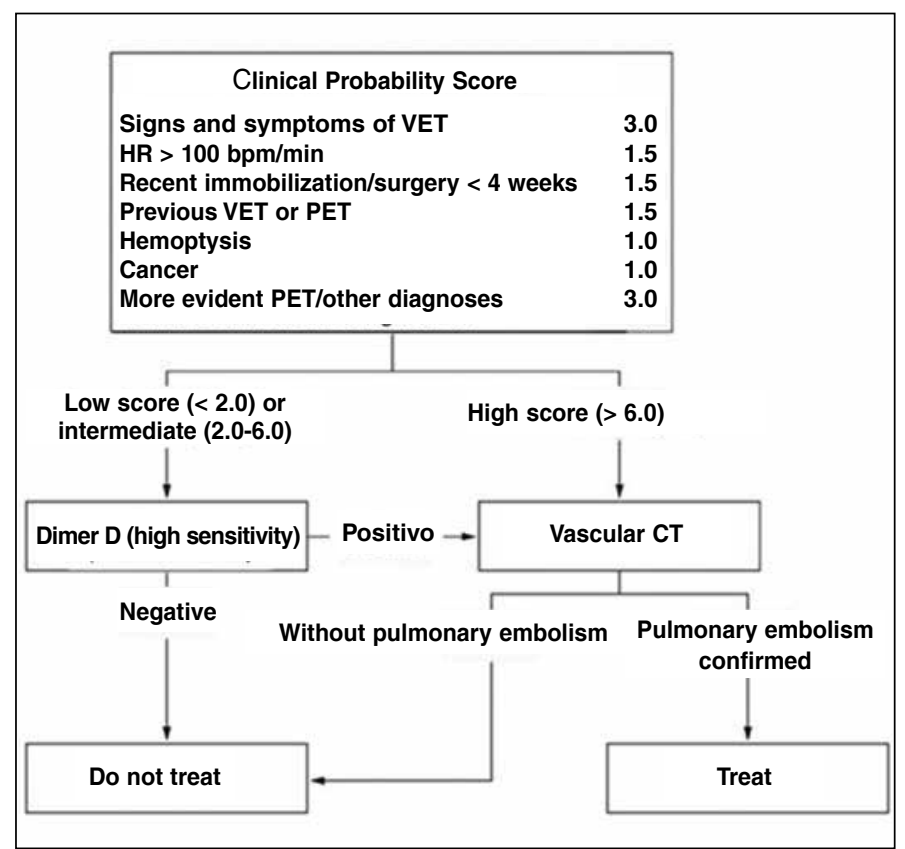

Figure 3 - Diagnostic algorithm for suspected PTE in patient without hypotension or shock.

Adapted from Konstantinides KS. Acute pulmonary embolism. N Engl J Med. 2008;395:2804-13.

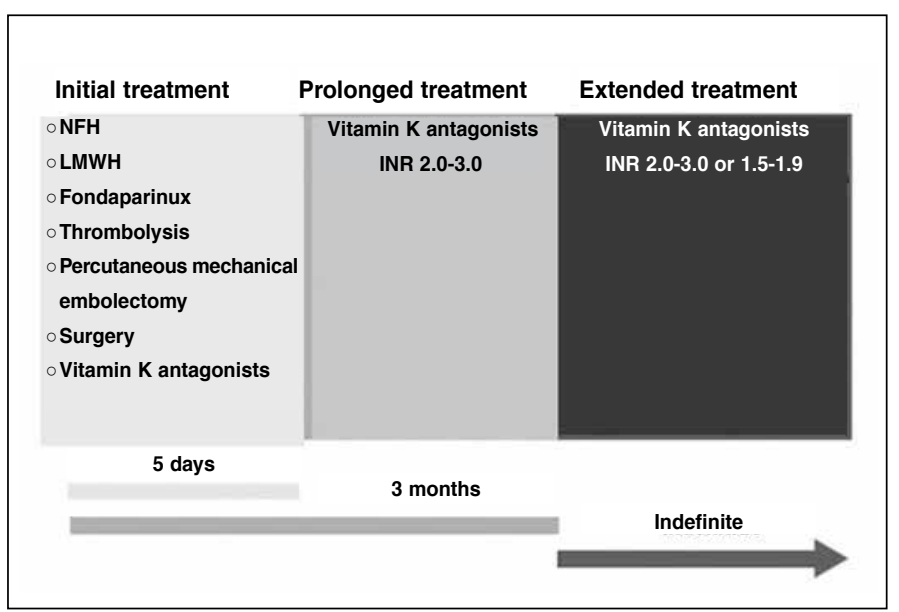

Figure 4 - Treatment regimen of PTE.

Adapted from Agnelli G, Becattini C. Acute pulmonary embolism. N Engl J Med. 2010;363:266-74.

\section{Other complications of DVT}

PTE is not the only complication of DVT. A patient with VTE can evolve to post-thrombotic syndrome (PTS), a circumstance characterized by vein ulceration by stasis, severe chronic pain in the leg, and untreatable edema of the ankle. In a study of 355 patients with DVT, the incidence of PTS was $17.5 \%$ after one year, $22.8 \%$ after two years, and $28 \%$ after five years $^{(25)}$.

\section{Prophylaxis}

Based on all the above mentioned characteristics, it is clear that prophylaxis of DVT is necessary in orthopedic procedures, and particularly, though not exclusively in arthroplasties.

Within this perspective, tools for raising awareness among professionals to follow the guidelines can play an important role ${ }^{(26)}$.

Orthopedic surgeons have generally demonstrated good awareness in the use of thromboprophylaxis, compared with professionals of other medical specialties. In 2008, a questionnaire to members of the American Association of Hip \& Knee Surgeons (AAHKS) showed that the majority of those questioned $(>80 \%)$ agreed with the preoperative assessment protocols of risk factors for VTE, and with postoperative prophylaxis (pharmacological and mechanical). Furthermore, $28 \%$ reported that they had changed their prophylactic practice in the last five years, in accordance with the ACCP and/or AAOS ${ }^{(27)}$.

A recent questionnaire of the American Association of Hip and Knee Surgeons indicated that $100 \%$ of their members used some method of prophylaxis for DVT. In 2003, the result (HIP and KNEE Registry) showed that one or more types of prophylaxis were carried out in $99 \%$ of patients. Approximately $89 \%$ of THA patients and $91 \%$ of TKA patients received prophylaxis according to the recommendations of the $7^{\text {th }} \mathrm{ACCP}^{(20)}$.

In our context, in hospitals of São Paulo, a study involving 1454 patients (589 surgical and 865 clinical) showed that despite the existence of various guidelines, thromboprophylaxis is not carried out appropriately: high-risk patients are undertreated, and low-risk patients are overtreated ${ }^{(28)}$.

This circumstance needs to be changed to ensure patients receive adequate treatment for the prevention of thromboembolism.

\section{VTE risk assessment}

A simplified risk assessment can be useful in the initial clinical assessment of the patient.

The Diretrizes (Guidelines) project, carried out in partnership with the Brazilian Medical Association and the Federal Council of Medicine, gives a clear picture of the risk assessment of DVT, and possible measures to be taken ${ }^{(29)}$ (Figure 5). 


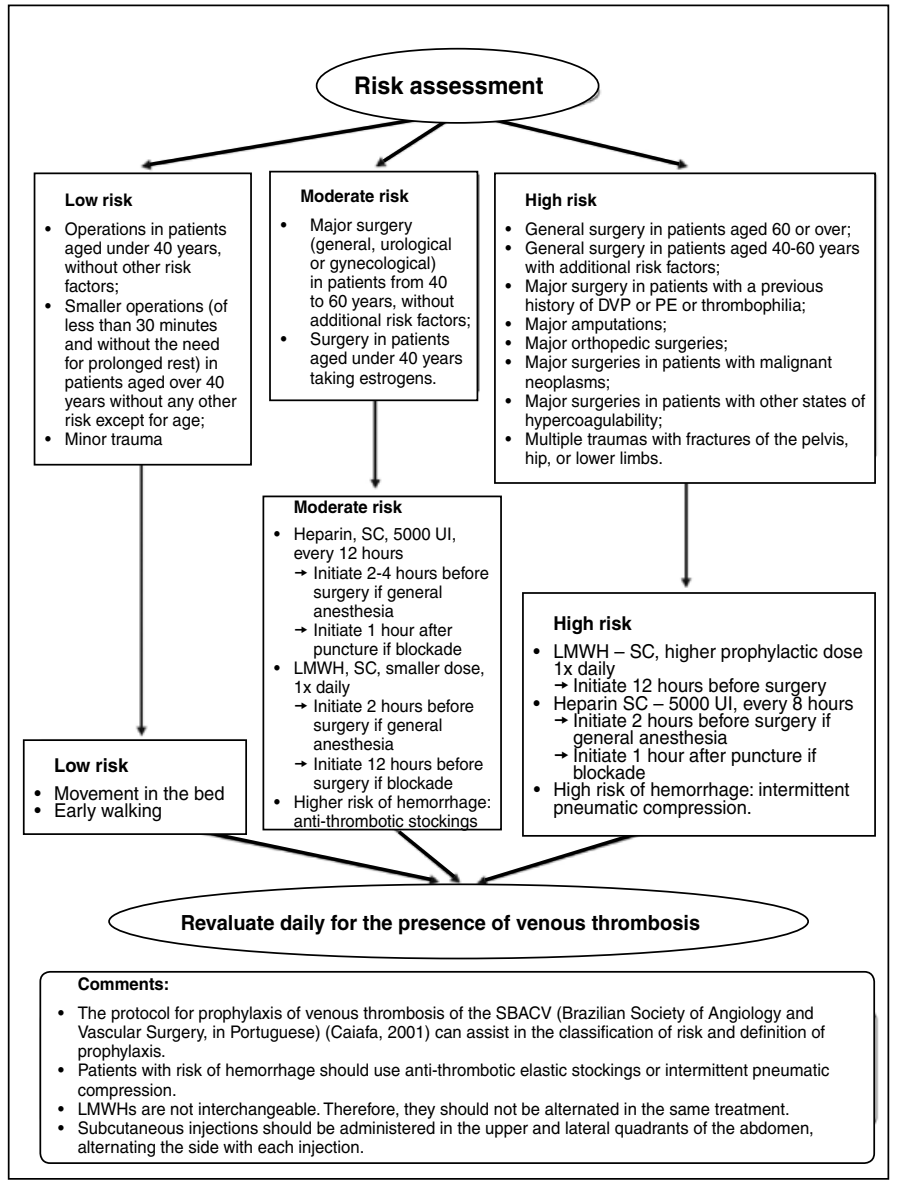

Figure 5 - Diretrizes (Guidelines) Project - DVT Guideline.JVasc Br. 2005;4(3):Supl 3.

\section{Methods of prophylaxis}

Although the use of low-molecular-weight heparin (LMWH) or non-fractionated heparins (NFH) represent the most common model of prophylaxis in our context, other alternatives can be listed, and critically considered. Initially, we can divide prophylaxis into mechanical and pharmacological.

\section{MECHANICAL PROPHYLAXIS}

\section{Early walking}

The most simple and possibly the most applicable method of prevention of venous stasis and DVT is, where possible, early walking.

Early walking is associated with a lower incidence of post-THA symptomatic $\mathrm{VTE}^{(30)}$. Also, stimulation of early walking associated with motor physiotherapy after hip fracture can be associated with an early return to the community, shorter hospitalization time, less complications, and low mortality after six months ${ }^{(31)}$.

\section{Mechanical methods}

Methods such as graduated elastic compression stockings (GECS), intermittent pneumatic compression (IPC), and plantar venous pump (PVP) increase blood flow and reduce venous stasis. These methods have the benefit that they have no risk of bleeding, presenting advantages in patients with an increased risk of bleeding. On the other hand, these methods may be difficult to implement or maintain, due to the limited movement of the patient and the discomfort they can bring. They are also contraindicated in situations such as exposed fracture, infection of the lower limbs, peripheral arterial insufficiency, severe cardiac insufficiency, and ulceration of the lower limbs.

The start of prophylaxis with mechanical methods may be the method of choice in patients with a high risk of bleeding; however, when this risk is temporary, prophylaxis should be initiated, by pharmacological means, as soon as the risk decreases. Another factor to be considered is irregular use of these methods, and training in their correct use, and they should only be discontinued for very short periods (during walking or when using the bathroom).

Current data ( $9^{\text {th }}$ ACCP) suggest the use of mechanical methods in addition to pharmacological prophylaxis during hospitalization, in patients with a high risk for DVT in major orthopedic surgeries ${ }^{(18)}$.

\section{Pharmacological prophylaxis}

Until a few years ago, heparin and warfarin were, in practice, the only drugs used in anticoagulant therapy. They are widely available, cheap, effective, and contain specific antidotes. However, they are considered problematic due to the need for their careful monitoring.

Warfarin has a slow onset of action, interacts with various drugs and foods, has a narrow therapeutic window, and has initial paradoxal prothrombic action.

Heparin requires monitoring when used for therapeutic purposes, and is associated with the development of thrombosis and bleeding, a condition known as heparin-induced thrombocytopenia (HIT).

\section{Platelet antiaggregants: acetylsalicylic acid (ASA) and clopidogrel}

Acetylsalicylic acid and clopidogrel are medications with permanent and temporary platelet aggregation inhibiting action, respectively. 
The use of ASA as a prophylactic agent for VTE is controversial. Although ASA is more effective than placebo in the prophylaxis of VTE the $9^{\text {th }}$ ACCP does not recommend its use as the sole prophylactic method in orthopedic surgeries, due to the lack of definitive evidence of its action, and the possibility of gastric alterations ${ }^{(18)}$.

While platelet antiaggregants are of little use in the prevention of venous thrombosis, they are essential in the prevention of arterial thrombosis, and can represent a risk in orthopedic procedures.

In fact, the need to deal with patients using ASA and clopidogrel in the prevention of coronary obstruction, and the use of pharmacological stents, may represent a challenge for the orthopedic team, since in these cases, suspending the medication can pose a risk of thrombosis of the stent. In this condition, the risks of suspending clopidogrel should we weighed against the risk of increased bleeding that is generated by double antiplatelet therapy ${ }^{(32)}$.

If the risk of bleeding is too high, the suspended antiplatelet therapy should be resumed as soon after surgery as is reasonably possible.

\section{warfarin}

Warfarin, through vitamin $\mathrm{K}$ blockade, is an inhibitor of gamma-carboxylation of various blood clotting factors (factors II, VII, IX, X, and proteins C and S). It does not act on the circulating clotting factors, only on their synthesis in the liver, which explains its delayed effect.

Although widely used in North America, here in Brazil, warfarin is little used as prophylaxis in orthopedic surgery, mainly due to its therapeutic variability, wide drug interactions, food interactions, and the need for laboratory monitoring.

When used, warfarin depends on the control of prothrombin activity through the measurement of the INR (International Normalized Ratio).

As an undesirable effect, warfarin presents, from the onset, a slight procoagulant effect, which may require concomitant use of heparin in the first 72 hours.

\section{tecarfarin}

Tecarfarin is a recent oral anticoagulant, of the vitamin K epoxide-reductase family of antagonists. Unlike warfarin, it is metabolized by esterases, and not by the cytochrome P450 system, thereby avoiding drug interactions. On the other hand, it appears to be more stable to control by the INR than warfarin. It is currently in phase III clinical trials, and is not yet available here in Brazil ${ }^{(33)}$.

\section{Non-fractionated heparin (NFH)}

Heparin is an activator of the blood enzyme antithrombin III. This enzyme inhibits various coagulation factors (II, IX and X) and more significantly, thrombin, which forms the fibrin thrombus. Non-fractionated heparin (NFH) is used in low doses by the subcutaneous (SC) route, which may be 10,000ui SC every 12 hours, or 5,000 ui SC every 8 hours. One of the most feared adverse effects is heparin-induced thrombocytopenia (HIT), in which there is formation of anti-heparin antibodies/ platelet factor, plateletopenia, with prothrombotic effect, which can develop bleeding, thrombosis and embolisms, and even death. When there is suspicion of HIT, heparin should be suspended immediately.

\section{Low-molecular-weight heparin (LMWH)}

This is obtained through the depolymerization of heparin and acts, mainly, blocking the factor Xa. It can be used subcutaneously, generally in a single daily application, without requiring laboratory monitoring. This means it can be applied safely and effectively in the patient's home. Currently, the most commonly used drugs in Brazil are:

- enoxaparin in the presentations of $20 \mathrm{mg}$ (used in patients with creatinine clearance $>30 \mathrm{ml} / \mathrm{min}$ ) or $40 \mathrm{mg}$, the dosage more commonly used as prophylaxis in orthopedic surgeries; and

- dalteparin in the 2,500 UI and 5,000 UI presentations.

Despite the possibility of developing HIT, various studies suggest that the incidence of HIT during prophylaxis with LMWH is lower when compared with NFH. Due to its safety and efficiency, enoxaparin is used today as gold standard for the development of new anticoagulant drugs.

\section{fondaparinux}

Fondaparinux is a pentasaccharide, whose antithrombotic activity is the result of selective inhibition of the factor Xa mediated by antithrombin III (ATIII). The neutralization of factor Xa interrupts the blood clotting cascade, thereby inhibiting the formation of thrombin and the development of the thrombus.

As a benefit over other injectable presentations, it does not inactivate thrombin (activated factor II), it has no effect on the platelets, and it does not cross-react with the serum of patients with heparin-induced thrombocytopenia.

A total of 144,806 patients were included in a study that showed a lower incidence of VTE with fondaparinux $(1.5 \%)$, compared with enoxaparin $(2.3 \%)$, dalteparin 
$(2.1 \%)$ and NFH (4.2\%). Significantly fewer patients in the fondaparinux group had some episode or were readmitted to hospital due to an episode of VTE, compared with those taking other medications ${ }^{(34)}$.

In patients with lowered renal function, particularly elderly diabetic patients and those with a high risk of bleeding, the dose of LMWH or fondaparinux should be reduced.

\section{New anticoagulant drugs}

\section{a) rivaroxaban}

Rivaroxaban is a highly selective, direct inhibitor of factor Xa, and is available by oral administration. The inhibition of factor $\mathrm{Xa}$ interrupts the intrinsic and extrinsic pathways of the clotting cascade, inhibiting the formation and development of thrombin. Rivaroxaban does not inhibit thrombin (activated factor II) and has no effect on the platelets ${ }^{(35)}$.

More than 9,500 patients (7,050 in THA and 2,531 in TKA) were evaluated in randomized, phase III, double-blind clinical trials known as the RECORD-programme. The dose used was rivaroxaban $10 \mathrm{mg}$, initiated up to 6 hours of closure of the surgical wound, compared with enoxaparin $40 \mathrm{mg} \mathrm{SC}$, initiated 12 hours before surgery.

Total DVT occurred in 79 out of 824 patients $(9.6 \%)$ who received rivaroxaban and in 166 out of $878(18.9 \%)$ who received enoxaparin (absolute risk reduction, 9.2\%); proximal DVT occurred in nine out of 908 patients $(1.0 \%)$ with rivaroxaban and in 24 out of $925(2.6 \%)$ with enoxaparin (absolute risk reduction, 1.6\%). Symptomatic events occurred less frequently with rivaroxaban than with enoxaparin $(p=0.005)$. Major bleeding in $0.6 \%$ of the patients of the rivaroxaban group and $0.5 \%$ of the patients of the enoxaparin group. The incidence of adverse effects, the majority gastrointestinal, was $12.0 \%$ with rivaroxaban and $13.0 \%$ with enoxaparin.

\section{b) dabigatran}

Dabigatran etexilate is a direct oral inhibitor of thrombin. Its efficacy was analyzed in studies that compare dabigatran etexilate (220 or $150 \mathrm{mg}$ per day) with enoxaparin. The first study ${ }^{(36)}$ involved a total of 2101 patients submitted to TKA (150 mg or 220 $\mathrm{mg}$ once daily) and the second ${ }^{(37)}$ involved a total of 3494 patients submitted to THA. In both studies, the main parameter of efficacy was the number of VTE or deaths by any cause during the treatment period.

In both studies, dabigatran etexilate was as effective as enoxaparin in preventing VTE or death.
Recently, however, studies have reported a relationship between the use of dabigatran and an increase of coronary events, including myocardial infarction ${ }^{(38)}$, which places its use in doubt, pending further studies.

\section{Current prophylaxis proposals}

The ninth edition (2012) of the evidence-based clinical guidelines of the American College of Chest Physicians ${ }^{(18)}$ contains guidelines for prevention in major orthopedic surgery, namely:

\section{Elective arthroplasty of the hip or knee}

Extended use after discharge up to the $35^{\text {th }}$ day after surgery of one of the following: LMWH and alternatively, fondaparinux, apixaban, dabigatran, rivaroxaban, NFH, Vitamin K antagonist, Aspirin ${ }^{\circledR}$ (polemic).

*During hospitalization: intermittent pneumatic compression (more than 18 hours/day).

\section{Hip fracture}

Extended use after discharge up to the $35^{\text {th }}$ day after surgery of one of the following: LMWH, and alternatively, fondaparinux, NFH, Vitamin K antagonist, Aspirin ${ }^{\circledR}$ (polemic).

*During hospitalization: intermittent pneumatic compression (more than 18 hours/day).

\section{Extended prophylaxis}

In a study from 1998, 19,586 THA and 24,059 TKA with cumulative incidence of VTE, the mean time to diagnosis was $2.8 \%$ and 2.1, respectively; after surgery, it was 17 days for THA and seven days for TKA. Although 88\% of these patients received prophylaxis while hospitalized, $76 \%$ and $74 \%$ of the thromboembolic events were diagnosed after discharge from hospital, and only $32 \%$ of these patients continued with the prophylaxis at home ${ }^{(8)}$.

A multicenter trial with 15,020 patients showed that those who received LMWH continued throughout every phase of the trial, i.e. even after discharge. However, approximately $37 \%$ of patients submitted to THA who initially received LMWH, did not continue to receive it after discharge, which is currently a recommendation of the ACCP Guidelines. By contrast, the duration of prophylaxis with warfarin with or without IPC was shorter ${ }^{(9)}$.

Currently, the recommendation is to maintain prophylaxis for VTE in patients submitted to THA and in the postoperative phase of fracture of the femur for at least four weeks, and in patients submitted to TKA, for 
at least ten days. Patients who have suffered spinal cord trauma, with total lesion of the spinal cord should receive anticoagulation medication for at least six weeks.

\section{Anesthetic blockade}

Systematic reviews have demonstrated that neuraxial blockade reduced cardiac and pulmonary morbidity and bleeding when compared with general anesthesia. Pain control and patient satisfaction are also improved with this method. Meanwhile, in patients using anticoagulant medications, a rare, but more devastating complication can occur: epidural or spinal cord hematoma ${ }^{(19)}$.

Some care should be taken to increase the safety of the anesthetic blockade in patients receiving or who will receive anticoagulants. For example: contraindicating anesthetic blockade in patients with clotting alterations.

Anti-inflammatories and ASA do not appear to increase the risk of subdural or spinal cord hematoma.

Clopidogrel should be suspended for at least seven days prior to the blockade.

\section{INDICATION}

\section{Total knee arthroplasty (TKA)}

For patients submitted to TKA, the following should be used:

- enoxaparin $40 \mathrm{mg}$ SC $1 \mathrm{x}$ daily, initiating up to 12 hours pre- or postoperative. Or if the above is not possible:

- dalteparin 5.000ui SC 1x daily, initiating up to 12 hours postoperative.

- dabigatran $110 \mathrm{mg}$, oral route, initiated 1 to 4 hours postoperative, 24 hours after the first dose, two 110 mg tablets together.

- rivaroxaban $10 \mathrm{mg}$, oral route, 1x daily, initiated 6 to 12 hours postoperative.

- Vitamin K blockers.

Prophylaxis should be used for at least 10 to 14 days, possibly extending to 35 days, depending on the associated risk factors.

The use of mechanical methods (IPC, GECS, PVP) should be associated with one of these pharmacological methods described above, during hospitalization.

In the case of high risk of bleeding, IPC may be used, until one of the above drugs can be introduced, or as an adjuvant method, if the patient has already presented previous DVT.

The use of NFH or ASA is not indicated, as these methods are less effective and/or safe.

\section{Total hip arthroplasty (THA)}

According to the 2012 Guidelines of the $9^{\text {th }}$ ACCP, prophylaxis with LMWH is recommended for at least four weeks, using the following:

- enoxaparin $40 \mathrm{mg} \mathrm{SC} \mathrm{1x}$ daily, initiating up to 12 hours pre- or postoperative. Or if the above is not possible:

- dalteparin 5.000ui SC 1x daily, initiating up to 12 hours postoperative.

- dabigatran $110 \mathrm{mg}$, oral route, initiated 1 to 4 hours postoperative, $24 \mathrm{~h}$ after the first dose, two $110 \mathrm{mg}$ tablets together.

- rivaroxaban $10 \mathrm{mg}$, oral route, $1 x$ daily, initiated 6 to 12 hours postoperative.

- vitamin K blockers.

Graduated elastic compression stockings may be used (20-30 $\mathrm{mmHg}$ in the ankle) throughout this period, in association with the pharmacological methods, decreasing still further the risk of VTE, as well as improving the edema, facilitating walking.

Prophylaxis should be used for at least 10 to 14 days, possibly extending to 35 days, depending on the associated risk factors.

\section{Knee arthroscopy}

In less aggressive surgeries, such as knee arthroscopy, the phenomenon of VTE can also be seen in studies using doppler US and venography in patients who have not received prophylaxis. These data suggest an incidence of $9.9 \%$ for total DVT and $2.1 \%$ for proximal $\mathrm{DVT}^{(35)}$, which makes the analysis of the risk of VTE and eventual prophylaxis interesting in these patients too. In young patients with no other risk factor for VTE, the only option should be early walking. No other method is indicated for prophylaxis in DVT.

For patients with some risk factor for VTE, or a complicated procedure, prophylaxis should be discussed, whether mechanical or pharmacological, which may be continued in the patient's home for up to seven days ${ }^{(39)}$.

\section{FINAL CONSIDERATIONS}

Thromboprophylaxis may represent one of the greatest benefits to be offered to a patient who requires - whether by choice or emergency - an orthopedic intervention, particularly arthroplasties of the lower limbs.

In an open analysis study of VTE in three years of 
follow-up at a university hospital with 3300 surgeries and 15,000 patients treated annually, the incidence of VTE in the classical high-risk groups in hip fracture, THA and TKA were low, with approximately $0.6 \%$, and that of pulmonary embolism of $0.27 \%$, with two cases of death by pulmonary embolism, occurring on

\section{REFERENCES}

1. Leclerc JR, Geerts WH, Desjardins L, Jobin F, Laroche F, Delorme F, Haviernick S,Atkinson S, Bourgouin J Prevention of deep vein thrombosis after major knee surgery - a randomized, doubleblind trial comparing a low molecular weight heparin fragment (enoxaparin) to placebo. Thromb Haemost. 1992;67(4):417-23.

2. Fidelis Júnior R, Amatuzzi MM.; Leão PP; Leme LEG. Trombose arterial relacionada à artroplastia total de joelho: revisão de literatura. Acta Ortop Bras. 2005;13(4):209-12.

3. Sharrock NE, Go G, Harpel PC, Ranawat CS, Sculco TP, Salvati EA. Throm bogenesis during total hip arthroplasty. Clin Orthop Relat Res 1995;(319):1-12.

4. Streiff MB, Haut EB. The CMS ruling on venous thromboembolism after total knee or hip arthroplasty: weighing risks and benefits. JAMA. 2009;301(10):1063-5.

5. Merli GJ. Pathophysiology of venous thrombosis, thrombophilia, and the diagnosis of deep vein thrombosis-pulmonary embolism in the elderly Clin Geriatr Med. 2006;22(1):75-92.

6. Rapaport SI. Hematologia: introdução. 2a. ed. São Paulo: Roca; 1990

7. Lieberman JR, Huo MM, Hanway J, Salvati EA, Sculco TP, Sharrock NE. The prevalence of deep venous thrombosis after total hip arthroplasty with hypotensive epidural anesthesia. J Bone Joint Surg Am. 1994;76(3):341-8.

8. Pellegrini VD Jr, Clement D, Lush-Elman C, Keller GS, Evarts CM. The natura history of thromboembolic disease following hospital dis- charge after tota hip arthroplasty: the case for routine surveillance. Clin Orthop Relat Res. 1996;(333): 27-40.

9. Geerts WH, Pineo GF, Heit JA, Bergqvist D, Lassen MR, Colwell CW, Ray JG Prevention of venous thromboembolism: the Seventh ACCP Conference on Antithrombotic and Thrombolytic Therapy. Chest. 2004;126(Suppl 3):338S-400.

10. Menzin J, Richner R, Huse D, Colditz GA, Oster G. Prevention of deep-vein thrombosis following total hip replacement surgery with enoxaparin versus unfractionated heparin: a pharmacoeconomic evaluation. Ann Pharmacother 1994;28(2):271-5.

11. Bredbacka S, Andreen M, Blombäck M, Wykman A. Activation of cascade systems by hip arthroplasty. No difference between fixation with and without cement. Acta Orthop Scand. 1987;58(3):231-5

12. Eriksson BI, Eriksson E, Gyzander E, Teger-Nilsson AC, Risberg B. Thrombosis after hip replacement. Relationship to the fibrinolytic system. Acta Orthop Scand. 1989;60(2):159-63.

13. Francis CW, Ricotta JJ, Evarts CM, Marder VJ. Long-term clinical observations and venous functional abnormalities after asymptomatic venous thrombosis following total hip or knee arthroplasty. Clin Orthop Relat Res. 1988;(232):271 8. PubMed PMID: 3383492.

14. Ginsberg JS, Turkstra F, Buller HR, MacKinnon B, Magier D, Hirsh J. Postthrombotic syndrome after hip or knee arthroplasty: a cross-sectional study. Arch Intern Med. 2000;160(5):669-72.

15. Kaboli $\mathrm{P}$, Henderson MC, White RH. DVT prophylaxis and anticoagulation in the surgical patient. Med Clin North Am. 2003;87(1):77-110.

16. Colwell CW Jr, Collis DK, Paulson R, McCutchen JW, Bigler GT, Lutz S, et al. Comparison of enoxaparin and warfarin for the prevention of venous thromboembolic disease after total hip arthroplasty. Evaluation during hospitalization and three months after discharge. J Bone Joint Surg Am. 1999;81(7):932-40.

17. Geerts WH, Bergqvist D, Pineo GF, Heit JA, Samama CM, Lassen MR, et al. Prevention of venous thromboembolism: American College of Chest Physicians Evidence-Based Clinical Practice Guidelines (8th Edition). Chest. 2008;133(6 Suppl):381S-453S.

18. Falck-Ytter Y, Francis CW, Johanson NA, Curley C, Dahl OE, Schulman S, et al. Prevention of VTE in orthopedic surgery patients: Antithrombotic Therapy and Prevention of Thrombosis, 9th ed: American College of Chest Physicians Eviden ce-Based Clinical Practice Guidelines. Chest. 2012;141(2 Suppl):e278S-325S.

19. Sweetland S, Green J, Liu B, Berrington de González A, Canonico M, Reeves $\mathrm{G}$, et al. Duration and magnitude of the postoperative risk of venous thromboembolism in middle aged women: prospective cohort study. BMJ. 2009 Dec 3;339:b4583. doi: 10.1136/bmj.b4583.

20. Warwick D, Friedman RJ, Agnelli G, Gil-Garay E, Johnson K, FitzGerald G, et al. Insufficient duration of venous thromboembolism prophylaxis after total hip or knee replacement when compared with the time course of thromboembolic events: findings from the Global Orthopaedic Registry. J Bone Joint Surg Br. 2007;89(6):799-807. days 72 and 109 after surgery. Patients with hip fractures had more VTE. The majority of cases of VTE occurred after discharge.

These data show us the importance of prophylaxis and its potential in the reduction of risks in orthopedic patients.

21. Seagroatt V, Tan HS, Goldacre M, Bulstrode C, Nugent I, Gill L. Elective total hip replacement: incidence, emergency readmission rate, and postoperative mortality. BMJ. 1991;303(6815):1431-5.

22. White RH, Romano PS, Zhou H, Rodrigo J, Bargar W. Incidence and time course of thromboembolic outcomes following total hip or knee arthroplasty. Arch Intern Med. 1998;158(14):1525-31.

23. Agnelli G, Becattini C. Acute pulmonary embolism. N Engl J Med. 2010;363(3):266-74

24. Konstantinides S. Clinical practice. Acute pulmonary embolism. N Engl J Med. 2008;359(26):2804-13

25. Prandoni $P$, Lensing AW, Cogo A, Cuppini S, Villalta S, Carta M, et al. The long-term clinical course of acute deep venous thrombosis. Ann Intern Med. 1996;125(1):1-7.

26. Paiva EF, Rocha ATC. Como implementar uma diretriz: da teoria à prática. Exemplo da profilaxia para tromboembolismo venoso. Acta Med Port. 2009;22(1):21-32

27. Markel DC. Venous Thromboembolism (VTE) screening, prophylaxis, evaluation \& management in adult hip \& knee arthroplasty: results of the 2008 survey of American Association of Hip \& Knee Surgeons (AAHKS). J Arthroplasty. 2009;24(2):e86

28. Deheinzelin D, Braga AL, Martins LC, Martins MA, Hernandez A, Yoshida WB, et al. Incorrect use of thromboprophylaxis for venous thromboembolism in medical and surgical patients: results of a multicentric, observational and cross-sectional study in Brazil. J Thromb Haemost. 2006;4(6):1266-70.

29. Maffei FHA, Caiafa JS, Ramacciotti E, Castro AA para o Grupo de Elaboração de Normas de Orientação Clínica em Trombose Venosa Profunda da SBACV. Normas de orientação clínica para prevenção, diagnóstico e tratamento da trombose venosa profunda (revisão 2005). Salvador: SBACV; 2005. Disponível em: URL: http://www.sbacv-nac.org.br

30. White RH, Gettner S, Newman JM, Trauner KB, Romano PS. Predictors of rehospitalization for symptomatic venous thromboembolism after total hip arthroplasty. N Engl J Med. 2000;343(24):1758-64.

31. Hoenig H, Rubenstein LV, Sloane R, Horner R, Kahn K. What is the role of timing in the surgical and rehabilitative care of community-dwelling older persons with acute hip fracture? Arch Intern Med. 1997;157(5):513-20.

32. Steele MJ, Fox JS, Fletcher JP, Grigg LE, Bell G. Clopidogrel dilemma for orthopaedic surgeons. ANZ J Surg. 2011;81(11):774-84.

33. Bavisotto LM, Ellis DJ, Milner PG, Combs DL, Irwin I, Canafax DM. Tecarfarin, a novel vitamin $\mathrm{K}$ reductase antagonist, is not affected by CYP2C9 and CYP3A4 inhibition following concomitant administration of fluconazole in healthy participants. J Clin Pharmacol. 2011;51(4):561-74.

34. Shorr AF, Kwong LM, Sarnes M, Happe L, Farrelly E, Mody-Patel N. Venous thromboembolism after orthopedic surgery: implications of the choice for prophylaxis. Thromb Res. 2007;121(1):17-24.

35. Ilahi OA, Reddy J, Ahmad I. Deep venous thrombosis after knee arthroscopy: ameta-analysis. Arthroscopy. 2005;21(6):727-30

36. Eriksson BI, Dahl OE, Büller HR, Hettiarachchi R, Rosencher N, Bravo ML, et al. A new oral direct thrombin inhibitor, dabigatran etexilate, compared with enoxaparin for prevention of thromboembolic events following total hip or knee replacement: the BISTRO II randomized trial. J Thromb Haemost. 2005;3(1):103-11.

37. Eriksson BI, Dahl OE, Rosencher N, Kurth AA, van Dijk CN, Frostick SP, et al. Oral dabigatran etexilate vs. subcutaneous enoxaparin for the prevention of venous thromboembolism after total knee replacement: the RE-MODEL randomized trial. J Thromb Haemost. 2007;5(11):2178-85.

38. Uchino K, Hernandez AV. Dabigatran association with higher risk of acute coronary events: meta-analysis of noninferiority randomized controlled trials. Arch Intern Med. 2012;172(5):397-402.

39. Camporese G, Bernardi E, Prandoni P, Noventa F, Verlato F, Simioni P, et al. Low-molecular-weight heparin versus compression stockings for thromboprophylaxis after knee arthroscopy: a randomized trial. Ann Intern Med. 2008;149(2):73-82. 